\title{
Teknologi dalam pengelolaan administrasi keuangan komite sekolah untuk meningkatkan transparansi \\ keuangan
}

\section{Dyah Ayu Megawaty ${ }^{1}$, Setiawansyah ${ }^{1 *}{ }^{*}$, Debby Alita ${ }^{1}, \&$ Putri Sukma Dewi ${ }^{2}$}

${ }^{1}$ Fakultas Teknik dan IImu Komputer, Universitas Teknokrat Indonesia, Indonesia

${ }^{2}$ Fakultas Sastra dan IImu Pendidikan, Universitas Teknokrat Indonesia, Indonesia

* setiawansyah@teknokrat.ac.id

\begin{abstract}
Sukoharjo State Vocational High School is one of the SMK in Pringsewu Regency. This vocational school is located on Jalan Wiyata No. 107 Sukoharjo III, Sukoharjo District, Pringsewu Regency. School committee finances are obtained based on the results of committee member meetings and determine the amount to be paid by students in 1 year, in the committee member meeting it is also explained that the receipt of payments made by students can be paid in monthly installments or paid at once by students and their parents. The school committee's financial activities are carried out through the process of planning, organizing, coordinating, supervising, or controlling. Some of the financial management activities are obtaining and determining funding sources, utilization of funds, reporting, inspection, and accountability. The school committee financial information system that has been used can perform financial management in a transparent and real-time manner, so that committee members can find out the school committee's finances by utilizing information technology without having to make a financial recapitulation of the school committee to be reported to committee members or administrators.
\end{abstract}

Abstrak Sekolah Menengah Kejuruan Negeri Sukoharjo adalah salah satu SMK Negeri di Kabupaten Pringsewu. SMK ini berada di Jalan Wiyata No 107 Sukoharjo III Kecamatan Sukoharjo, Kabupaten Pringsewu. SMK ini merupakan SMK Negeri satu-satunya yang ada di Kecamatan Sukoharjo. Keuangan komite sekolah didapat berdasarkan hasil rapat anggota komite dan menetapkan jumlah yang harus dibayar oleh siswa dalam 1 tahun, dalam rapat anggota komite juga dijelaskan penerimaan pembayaran yang dilakukan oleh siswa dapat dicicil secara perbulan ataupun dibayar sekaligus oleh siswa dan orang tua siswa. Kegiatan keuangan komite sekolah dilakukan melalui proses perencanaan, pengorganisasian, pengkoordinasian, pengawasan atau pengendalian. Beberapa kegiatan manajemen keuangan yaitu memperoleh dan menetapkan sumbersumber pendanaan, pemanfaatan dana, pelaporan, pemeriksaan dan pertanggungjawaban. Sistem informasi keuangan komite sekolah yang telah digunakan dapat melakukan menajemen keuangan secara transparansi dan realtime, sehingga anggota komite atau pengurus komite dapat mengetahui keuangan komite sekolah dengan memanfaatkan teknologi informasi tanpa harus membuat rekapitulasi keuangan komite sekolah untuk dilaporkan kepada anggota atau pengurus komite.

Keywords: information; finance; committee; realtime; SMKN Sukoharjo

\section{ठ OPEN ACCESS}

Citation: Megawaty, D. A., Setiawansyah, D. Alita, \& P. S. Dewi. (2021). Teknologi dalam pengelolaan administrasi keuangan komite sekolah untuk meningkatkan transparansi keuangan. Riau Journal of Empowerment, 4(2), 95-104. https://doi.org/10.31258/raje.4.2.95-104

Received: 2020-11-25 Revised: 2021-04-13 Accepted: 2021-04-19

Language: Bahasa Indonesia (id)

ISSN 2623-1549 (online), 2654-4520 (print)

(C2021 Dyah Ayu Megawaty, Setiawansyah, Debby Alita, \& Putri Sukma Dewi. Author(s) retain the copyright of article published in this journal, with first publication rights granted to Riau Journal of Empowerment. The article is licenced under Creative Commons Attribution 4.0 International License. This license permits unrestricted use, distribution, and reproduction in any medium, provided the original author and source are credited. 


\section{PENDAHULUAN}

Sekolah Menengah Kejuruan (SMK) adalah Lembaga Pendidikan Formal yang menyelenggarakan Pendidikan Kejuruan, pada jenjang Pendidikan Menengah sebagai lanjutan dari SMP/MTs. Pendidikan Kejuruan merupakan pendidikan menengah yang mempersiapkan Program Keahlian untuk peserta didiknya. Lembaga pendidikan formal seperti SMK pastinya memerlukan pencatatan keuangan komite yang baik untuk kebutuhan siswa. Maka dalam memberikan kontribusi dalam pembangunan bangsa diperlukan manajemen sistem yang efektif san efisien, salah satunya sistem pencatatan keuangan (Maulida et al., 2020).

Dalam penyelengaraan pendidikan keuangan merupakan hal yang sangat penting dalam proses pendidikan dan potensi yang sangat menentukan jalannya suatu proses pendidikan. Komponen keuangan merupakan komponen produksi yang menentukan proses terlaksananya kegiatan-kegitan proses belajar mengajar dalam sekolah dengan komponen-kompenen lainnya, maka dari itu semua kegiatan yang dilakukan sekolah memerlukan biaya baik yang disadari ataupun tidak disadari oleh penyelenggara pendidikan terutama bagian keuangan komite sekolah. Komite Sekolah adalah lembaga mandiri yang beranggotakan orangtua/wali peserta didik, komunitas sekolah, serta tokoh masyarakat yang peduli pendidikan. Komite Sekolah diatur dengan Permendikbud Nomor 75 Tahun 2016 tentang Komite Sekolah. Peraturan Menteri Pendidikan Dan Kebudayaan Nomor 75 Tahun 2016 Tentang Komite Sekolah ditetapkan oleh Mendikbud. Tugas Komite Sekolah adalah memberikan pertimbangan dalam penentuan dan pelaksanaan kebijakan pendidikan, menggalang dana dan sumber daya pendidikan lainnya dari masyarakat baik perorangan/organisasi/dunia usaha/dunia industri maupun pemangku kepentingan lainnya melalui upaya kreatif dan inovatif, mengawasi pelayanan pendidikan di Sekolah sesuai dengan ketentuan peraturan perundang-undangan, dan menindaklanjuti keluhan, saran, kritik, dan aspirasi dari peserta didik, orangtua/wali, dan masyarakat serta hasil pengamatan Komite Sekolah atas kinerja Sekolah.

Sekolah Menengah Kejuruan Negeri Sukoharjo adalah salah satu SMK Negeri di Kabupaten Pringsewu. SMK ini berada di Jalan Wiyata No 107 Sukoharjo III Kecamatan Sukoharjo, Kabupaten Pringsewu. SMK ini merupakan SMK Negeri satu-satunya yang ada di Kecamatan Sukoharjo. SMK ini memiliki 6 jurusan yaitu Jurusan Teknik Instalasi Tenaga Listrik (TITL), Jurusan Teknik Kendaraan Ringan Otomotif (TKRO), Jurusan Teknik dan Bisnis Sepeda Motor (TBSM), Jurusan Teknik Komputer dan Jaringan (TKJ), Jurusan Multimedia (MM), dan Jurusan Animasi. SMK Negeri Sukoharjo memiliki 32 ruang kelas belajar, 2 laboratorium, 1 perpustakaan. Total dari 5 jurusan yang dimiliki jumlah perserta didik berjumlah 1032 siswa/i, serta memiliki 55 guru/tenaga pendidik, 30 Rombongan Belajar. Selain sebagai penyelenggara pendidikan, keberadaan SMK Negeri Sukoharjo diharapkan dapat berperan sebagai motivator, dinamisator, dan akselerator pembangunan daerah. Dalam kaitan tersebut, SMKN Sukoharjo terus melaksanakan aktivitas dan fasilitas akademik dengan memperluas penyelenggaraan bidang studi guna mencetak lulusan yang professional disejumlah bidang pengetahuan khusus.

Keuangan komite sekolah didapat berdasarkan hasil rapat anggota komite dan menetapkan jumlah yang harus dibayar oleh siswa dalam 1 tahun, dalam rapat anggota komite juga dijelaskan penerimaan pembayaran yang dilakukan oleh siswa dapat dicicil secara perbulan ataupun dibayar sekaligus oleh siswa dan orang tua siswa. Kegiatan keuangan komite sekolah dilakukan melalui proses perencanaan, pengorganisasian, pengarahan, pengkoordinasian, pengawasan atau pengendalian (Kaleb, 2019). Beberapa kegiatan manajemen keuangan yaitu 
memperoleh dan menetapkan sumber-sumber pendanaan, pemanfaatan dana, pelaporan, pemeriksaan dan pertanggungjawaban (Ahmad et al., 2019). Di dalam manajemen keuangan sekolah terdapat rangkaian aktivitas terdiri dari perencanaan program sekolah, perkiraan anggaran, dan pendapatan yang diperlukan dalam pelaksanaan program, pengesahan dan penggunaan anggaran sekolah (Ahdan \& Sari, 2020). Manajemen keuangan dapat diartikan sebagai tindakan pengurusan/ ketatausahaan keuangan yang meliputi pencatatan, perencanaan, pelaksanaan, pertanggungjawaban dan pelaporan. Dengan demikian manajemen keuangan sekolah merupakan rangkaian aktivitas mengatur keuangan komite sekolah. Melalui kegiatan manajemen keuangan maka kebutuhan pendanaan kegiatan sekolah dapat direncanakan, diupayakan pengadaannya, dibukukan secara transparan, dan digunakan untuk membiayai pelaksanaan program sekolah secara efektif dan efisien (Sulistiani et al., 2020). Untuk itu tujuan manajemen keuangan adalah Meningkatkan efektivitas dan efisiensi penggunaan keuangan sekolah, Meningkatkan akuntabilitas dan transparansi keuangan sekolah, dan Meminimalkan penyalahgunaan anggaran sumbangan komite sekolah (Atmadja \& Saputra, 2017).

Berdasarkan latar belakang, pihak mitra yaitu SMK Negeri Sukoharjo mengusulkan untuk dibuatkannya aplikasi keuangan Komite Sekolah kepada tim pengusul PKM dari Universitas Teknokrat Indonesia dan memberikan penyuluhan, pengembangan, pelatihan dan pendampingan penggunaan teknologi informasi keuangan komite sekolah (Setiawan \& Nurjaman, 2017). Pihak sekolah berharap dengan adanya aplikasi keuangan Komite Sekolah ini maka akan dapat meningkatkan kemampuan dan pengetahuan bagian keuangan komite sekolah dalam pengelolaan keuangan komite sekolah secara transparansi dan realtime untuk dapat diketahui oleh seluruh anggota komite sekolah dengan memanfaatkan teknologi informasi (Yana et al., 2020).

\section{METODE PENERAPAN}

\section{Tahapan pengabdian}

Metode pelaksanaan yang digunakan dalam kegiatan pengabdian masyarakat adalah Penerapan Teknologi Dalam Pengelolaan Administrasi Keuangan Komite Untuk Meningkatkan Transparansi Keuangan pada SMK Negeri Sukoharjo, kemudian melakukan pelatihan dan pendampingan kepada bagian keuangan dan anggota atau pengurus komite dalam menggunakan aplikasi keuangan komite sekolah guna untuk menyelesaikan permasalahan. Adapun tahapan pelaksanaan yang dilakukan yaitu: 


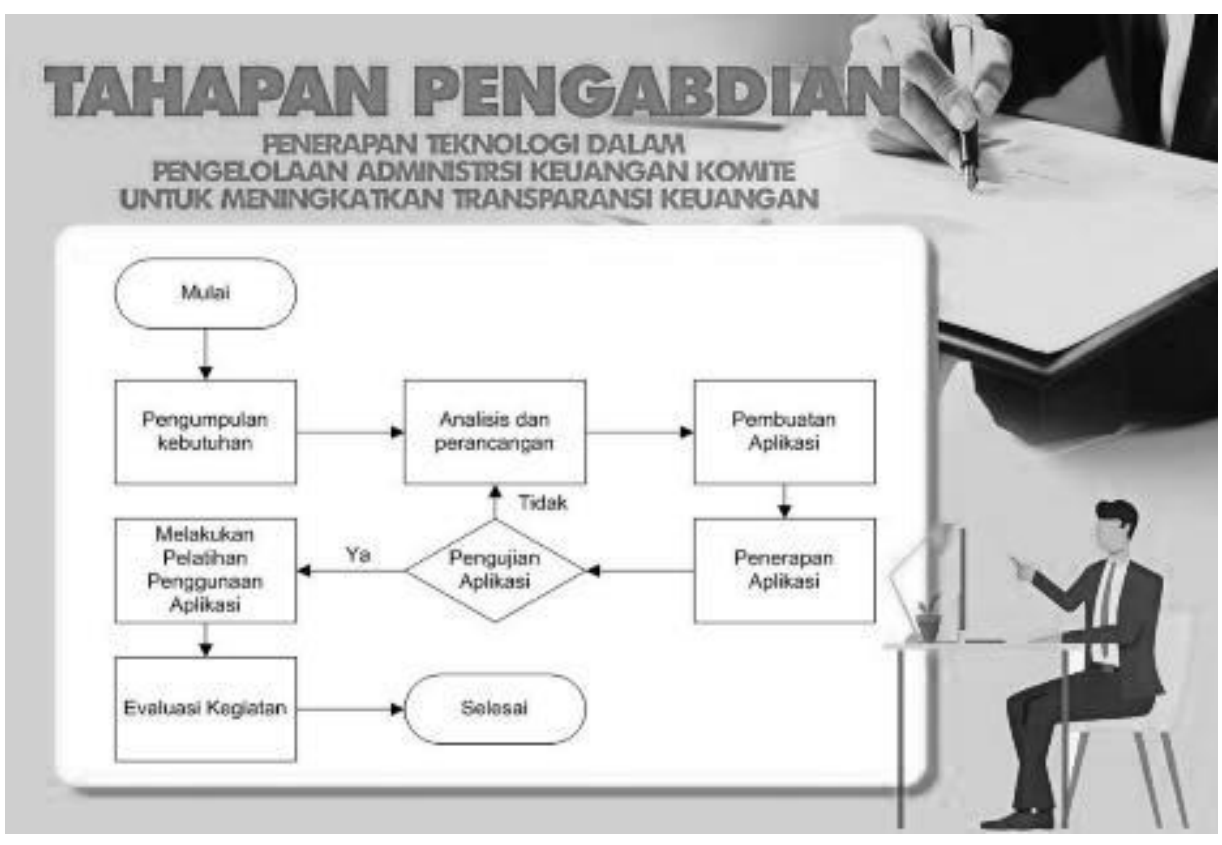

Gambar 1. Tahapan Kegiatan Pengabdian Kepada Masyarakat

Tahapan pelaksanaan pengabdian kepada masyarakat yang dilakukan:

1. Pengumpulan Kebutuhan

Pada tahapan ini tim pengusul bersama mitra membuat kebutuhan terkait dengan aplikasi yang akan dikembangkan, peran mitra yaitu SMK Negeri Sukoharjo yaitu memberikan masukkan kepada tim pengusul terkait tentang alur pengelolaan keuangan komite sekolah mulai dari penerimaan, pengeluaran, dan pelaporan keuangan komite sekolah.

2. Analisis dan Perancangan

Setelah mengetahui tentang gambaran aplikasi yang dibutuhhkan mitra, selanjutnya tim pengusul membuat analisis dan perancangan untuk aplikasi yang akan digunakan, pada tahapan analisis kegiatan yang dilakukan adalah membuat kebutuhan fungsional dan non fungsional dari aplikasi yang akan dibuat, sedangkan pada tahapan perancangan kegiatan yang dilakukan adalah merancang basis data, dan prototype aplikasi pengelolaan administrasi keuangan komite sekolah.

3. Pembuatan Aplikasi

Tahapan ini merupakan proses pembuatan aplikasi pengelolaan administrasi keuangan komite sekolah sesuai dengan kebutuhan, analisis dan perancangan yang telah dilakukan pada tahapan sebelumnya. Aplikasi yang digunakan adalah CodeIgniter 4.0 dengan menggunakan basis data $M y S Q L$, dan aplikasi akan dihosting pada server sekolah.

4. Penerapan Aplikasi

Setelah aplikasi selesai, selanjutnya agar aplikasi dapat diakses secara online, maka aplikasi pengelolaan administrasi keuangan tersebut harus dihosting agar dapat diuji coba secara langsung melalui koneksi internet.

5. Pengujian Aplikasi

Sebelum aplikasi digunakan oleh pihak SMK Negeri Sukoharjo, aplikasi ini terlebih dahulu diuji apakah masih terdapat error dan apakah sudah sesuai dengan kebutuhan yang diharapkan oleh mitra. Proses pengujian melibatkan pakar dan pihak mitra, dimana pakar yang akan menguji dari sisi fungsionalitas aplikasi yaitu 3 orang dengan bidang keilmuan Software Enginering sedangkan mitra menguji dari sisi kebutuhan yang mereka harapkan dan jika aplikasi masih belum sesuai, maka aplikasi harus diperbaiki terlebih dahulu, namun jika sudah sesuai maka dapat dilanjutkan pada tahap berikutnya. 
6. Pelatihan Penggunaan Aplikasi

Kegiatan ini merupakan tahapan untuk meningkatkan keterampilan dan kemampuan mitra dalam penggunaan aplikasi pengelolaan administrasi keuangan komite sekolah para staff bagian keuangan komite akan dibekali pengetahuan tentang bagaimana menggunakan aplikasi dan pelakukan pengolahan data keuangan komite secara online.

7. Evaluasi Kegiatan

Pada tahapan ini akan dilakukan evaluasi dengan menyebar kuisioner kepada staff bagian keuangan dan anggota komite untuk mengukur tingkat keterampilan dan kemampuan dalam pengelolaan dan pemanfaatan aplikasi pengelolaan administrasi keuangan komite sekolah di SMK Negeri Sukoharjo. Kuisioner menggunakan indikator yang dikenalkan oleh DeLone and McLean digunakan sebagai model mengukur kesuksesan informasi aplikasi keuangan komite sekolah.

\section{Gambaran IPTEK}

Gambaran iptek digunakan sebagai landasan penerapan PKM yang akan dilaksanakan kepada mitra. Gambaran Iptek yang akan dilaksanakan dapat dilihat pada gambar berikut ini:

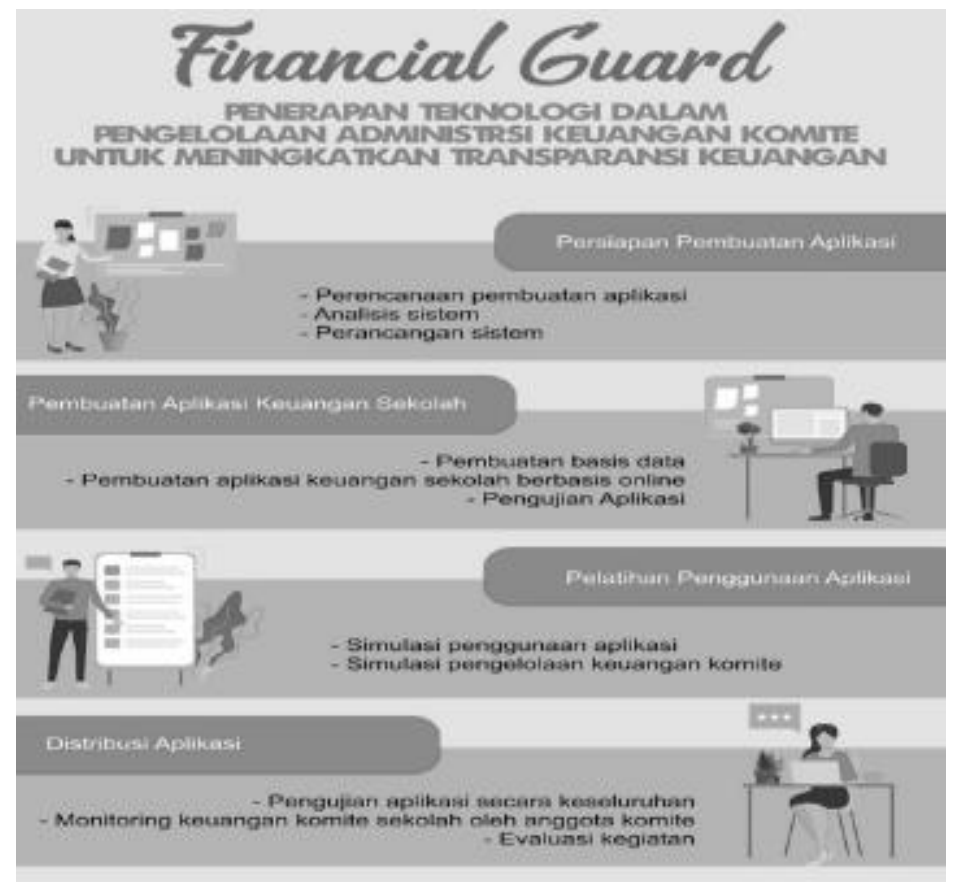

Gambar 2. Gambaran IPTEK

Penjelasan gambaran Iptek yaitu

1. Proses pertama yang harus dilakukan adalah persiapan pembuatan aplikasi pengelolaan keuangan komite sekolah yaitu perencanaan pembuatan aplikasi. Hal-hal yang harus dipersiapkan adalah mulai dari menganalisis kebutuhan sistem pengelolaan keuangan komite sekolah, selanjutnya melakukan perancangan sistem berdasarkan analisis yang telah dilakukan untuk memenuhi kebutuhan sekolah.

2. Proses kedua adalah pembuatan aplikasi aplikasi pengelolaan administrasi keuangan komite sekolah dengan menggunakan teknologi berbasis web dari CodeIgniter dan dilanjutkan dengan pembuatan aplikasi, dan melakukan pengujian aplikasi (Setiawansyah et al., 2020).

3. Proses ketiga adalah Pelatihan penggunaan aplikasi, dalam tahapan ini melakukan pelatihan kepada staff bagian keuangan dan anggota komite sekolah untuk menggunakan aplikasi pengelolaan administrasi keuangan komite sekolah. 
4. Distribusi aplikasi, yaitu melakukan pengujian terhadap keseluruhan fitur yang ada pada aplikasi pengelolaan administrasi keuangan komite sekolah, serta memberi penjelasan tentang monitoring keuangan komite sekolah oleh anggota dan pengurus komite sekolah untuk menghasilkan sistem keuangan yang transparansi dan realtime yang dibisa diakses oleh semua anggota dan pengurus komite sekolah.

\section{HASIL DAN KETERCAPAIAN SASARAN}

Tahapan pelaksanaan kegiatan pengabdian kepada masyarakat pada SMK Negeri Sukoharjo Pringsewu ini membuat aplikasi keuangan komite sekolah yang akan mengatasi permasalahan pada mitra yaitu belum adanya aplikasi yang dapat sistem keuangan Komite Sekolah secara transparansi dan realtime (Andriyanto et al., 2019), tetapi sudah memiliki sumber daya manusia yang baik dalam pengelolaan keuangan komite sekolah, belum optimalnya kemampuan serta pengetahuan bagian keuangan komite sekolah dalam memanfaatkan teknologi untuk menghasilkan keuangan Komite Sekolah secara transparansi dan realtime, dalam pengelolaan keuangan komite sekolah dalam hal penerimaan dan pengeluaran keuangan masih mencatat dalam buku besar untuk penerimaan dan pengeluaran keuangan komite sekolah dan dalam menghasilkan informasi tentang rekapitulasi keuangan komite sekolah bagian keuangan komite sekolah harus merekap data keuangan terlebih dahulu untuk dilaporkan kepada anggota komite sekolah dalam rapat anggota komite sekolah.

Berdasarkan hasil analisis yang telah dilakukan maka aplikasi keuangan komite sekolah mempunyai fitur login, mengelola data siswa, mengelola tahun ajaran, mengelola jenis pengeluaran, mengelola data kelas siswa, mengelola data potongan sumbangan komite, mengelola data pembayaran sumbangan komite, mengelola pengeluaran sumbangan komite, laporan pembayaran sumbangan komite, pengeluaran sumbangan komite, keuangan komite, dan logout.

Tampilan antar muka (user interface) aplikasi keuangan komite sekolah terdapat pada gambar berikut ini:

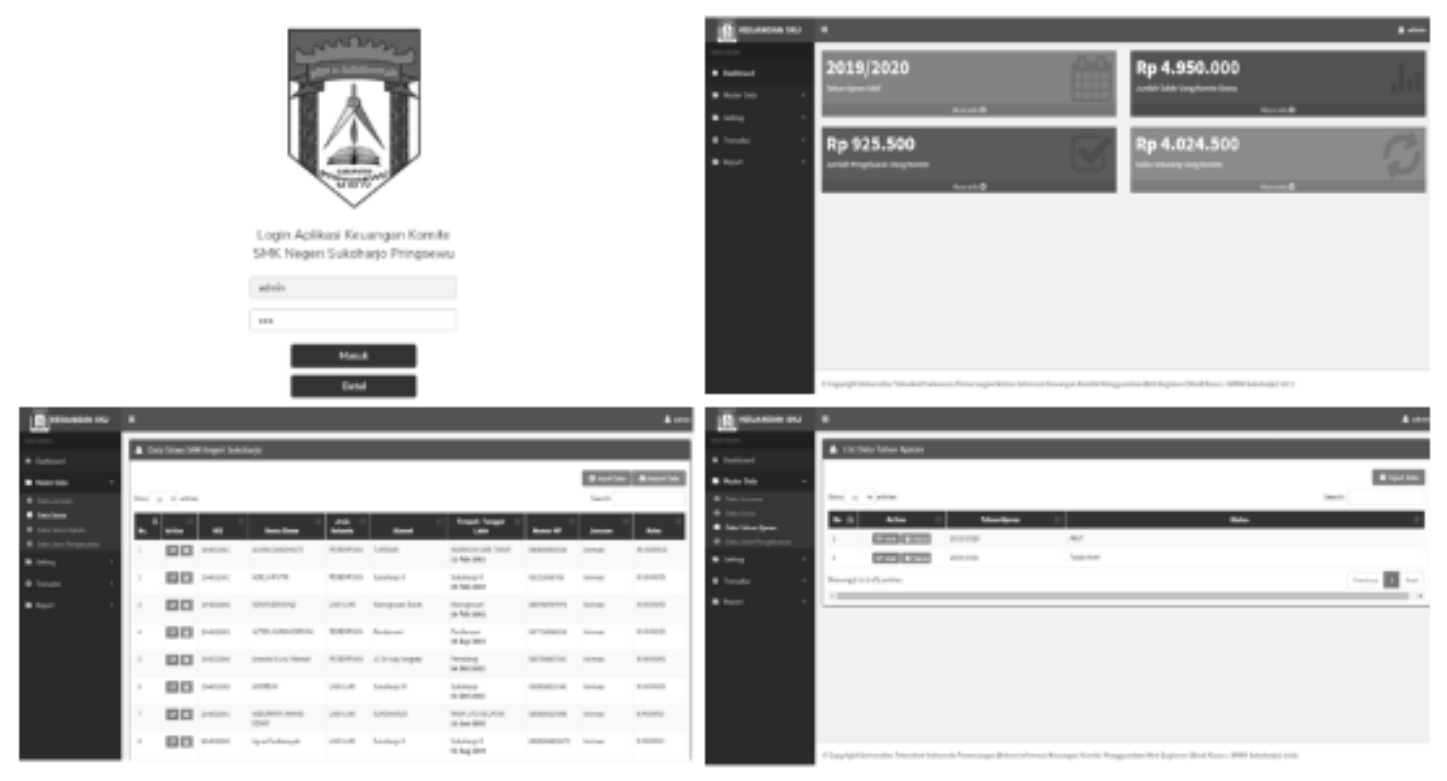



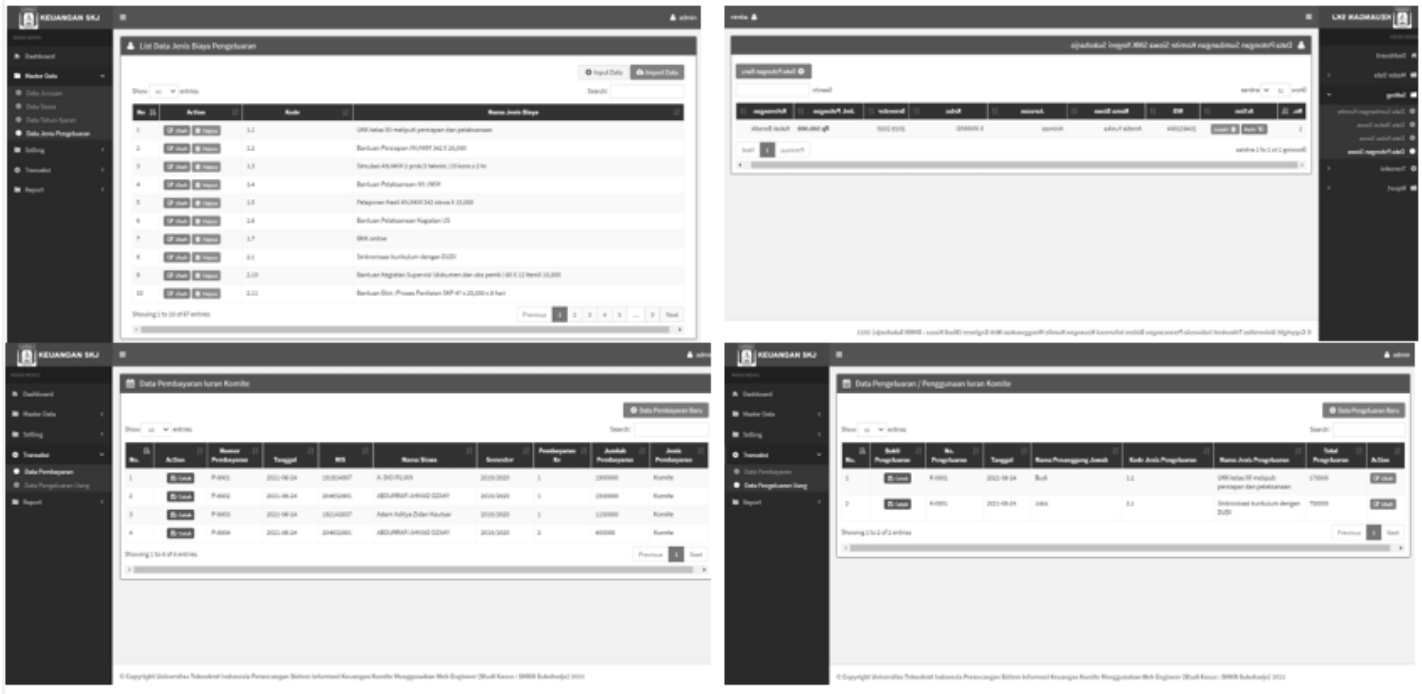

Megawaty

et al.

Gambar 2. User interface Aplikasi Keuangan Komite Sekolah

Pengguna aplikasi keuangan komite sekolah terdiri dari Bagian Keuangan komite sekolah, Kepala Sekolah, Anggota Komite Sekolah. Bagian Keuangan komite sekolah mempunya fitur login, dashboard, mengelola data siswa, mengelola data tahun ajaran, mengelola data jenis pengeluaran, mengelola data sumbangan komite, mengelola data kelas siswa, mengelola data potongan sumbangan komite, mengelola data pembayaran sumbangan komite, mengelola data pengeluaran sumbangan komite, laporan pembayaran sumbangan komite, laporan pengeluaran sumbangan komite, dan laporan keuangan komite sekolah. Kepala Sekolah dan Anggota Komite Sekolah mempunyai fitur login, dashboard, laporan pembayaran sumbangan komite, laporan pengeluaran sumbangan komite, dan laporan keuangan komite sekolah.

Pelatihan dan workshop penggunaan aplikasi keuangan komite sekolah dilakukan dengan melibatkan Bagian Keuangan, Kepala Sekolah, dan Anggota Komite Sekolah. Materi dalam kegiatan ini meliputi penerapan teknologi yang digunakan dalam aplikasi keuangan komite sekolah, pendampingan penerapan aplikasi keuangan komite dalam penginputan data siswa, data tahun ajaran, data jenis pengeluaran, data sumbangan komite, data potongan sumbangan komite, data pembayaran sumbangan komite, data pengeluaran keuangan komite untuk meningkatkan transparansi dan realtime untuk dapat diketahui oleh seluruh anggota komite sekolah dengan memanfaatkan teknologi informasi (Kumala et al., 2020). 

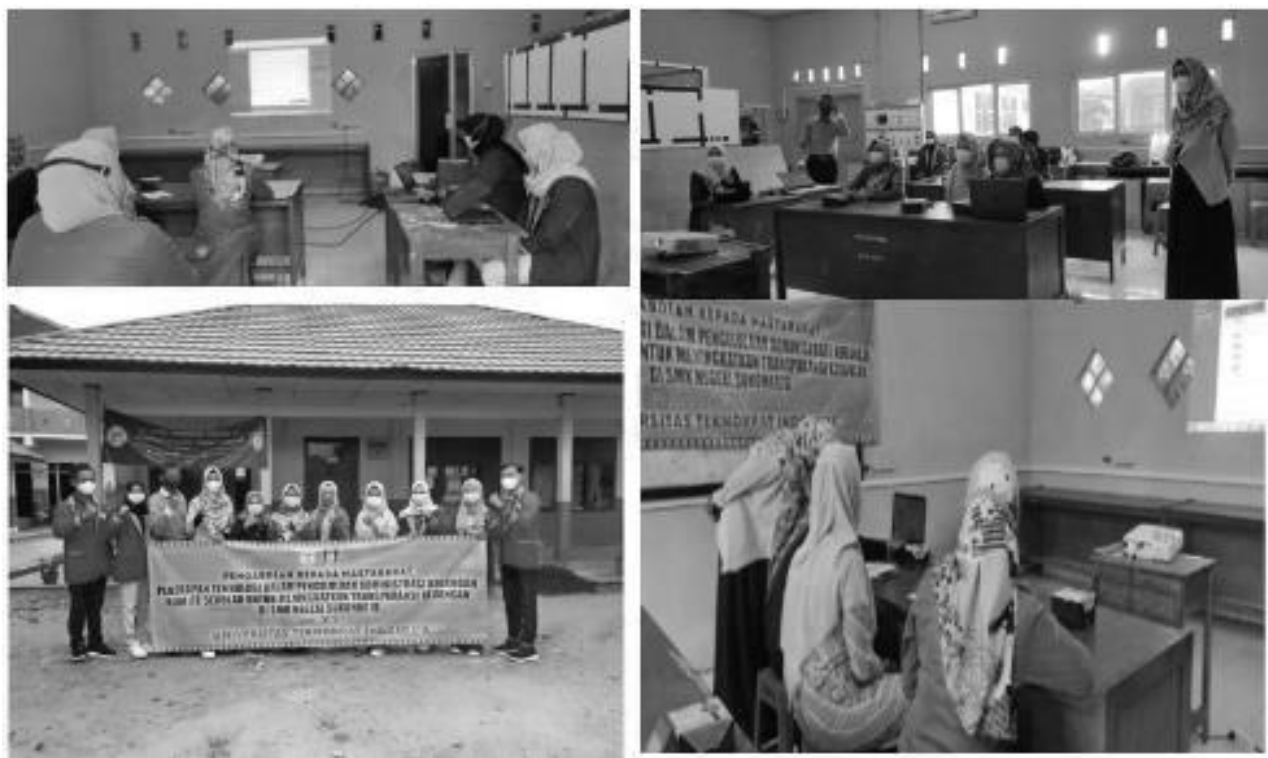

Gambar 3. Pelatihan dan Workshop Penggunaan Aplikasi Keuangan Komite

Pengujian black box untuk mengetahui kesesuaian fungsi pada aplikasi keungan komite yang dibangun. Pengujian black box testing ini mempunyai 14 komponen pengujian yang sudah dilakukan pengujian kepada 3 responden dengan jabatan dosen Universitas Teknokrat Indonesia yang mempunyain bidang keahlian software engineering. Berikut ini adalah hasil pengujian yang telah dilakukan.

Tabel 1. Hasil Pengujian Blackbpx Testing

\begin{tabular}{lcc}
\hline \multicolumn{1}{c}{ Kriteria Pengujian } & \multicolumn{2}{c}{ Hasil Pengujian } \\
& Sesuai & Tidak Sesuai \\
\hline Halaman Login & 12 & 0 \\
Halaman Data Dashboard & 12 & 0 \\
Halaman Data Siswa & 12 & 0 \\
Halaman Data Jurusan & 12 & 0 \\
Halaman Data Tahun Ajaran & 9 & 0 \\
Halaman Data Jenis Pengeluaran & 9 & 0 \\
Halaman Data Sumbangan Komite & 6 & 0 \\
Halaman Data Kelas Siswa & 6 & 0 \\
Halaman Data Potongan Sumbangan Komite & 6 & 0 \\
Halaman Data Pembayaran Sumbangan Komite & 6 & 0 \\
Halaman Data Pengeluaran Sumbangan Komite & 6 & 0 \\
Halaman Laporan Pembayaran Sumbangan Komite & 6 & 0 \\
Halaman Laporan Pengeluaran Sumbangan Komite & 6 & 0 \\
Halaman Laporan Keuangan Komite & 6 & 0 \\
\hline$\quad$ Total Jawaban & 126 & 0 \\
\hline
\end{tabular}


Berdasarkan hasil rekapitulasi 14 kriteria pengujian yang telah dilakukan didapatkan hasil jumlah jawaban dari responden yaitu mempunyai nilai 100\% sesuai dengan pengujian fungsionalitas sistem menggunakan blackbox testing.

Pengujian kualitas informasi dari prototype dengan model DeLone and McLeon akan memaparkan hasil kualitas informasi berdasarkan masing-masing kriteria yaitu Kualitas Informasi (KI), Kualitas Sistem (KS), Kualitas Layanan (KL), Penggunaan (P), dan Kepuasan Pelanggan (KP). Selain itu juga pengujian ini akan dipaparkan hasil keseluruhan kualitas prototype yang dibuat, berdasarkan tanggapan 12 responden dari pengguna aplikasi keuangan komite yang telah mengisi kuisioner dan diukur dengan rumus sebagai berikut:

Megawaty

et al.

\section{3}

Tabel 2. Hasil Pengujian Model DeLone and McLean

\begin{tabular}{clcccc}
\hline \multirow{2}{*}{ No } & \multicolumn{1}{c}{ Aspek / Kriteria } & $\begin{array}{c}\text { Skor } \\
\text { Aktual }\end{array}$ & $\begin{array}{c}\text { Skor } \\
\text { Ideal }\end{array}$ & $\begin{array}{c}\text { \% Skor } \\
\text { Total }\end{array}$ & Kriteria \\
\hline 1 & Kualitas Informasi (Information Quality) & 121 & 150 & 80,67 & Baik \\
2 & Kualitas Sistem (System Quality) & 122 & 150 & 81,33 & Baik \\
3 & Kualitas Layanan (Service Quality) & 74 & 90 & 82,22 & Baik \\
4 & Penggunaan (Use) & 48 & 60 & 80 & Baik \\
5 & Kepuasan Pengguna (Use Satisfaction) & 50 & 60 & 83,33 & Baik \\
\hline & $\quad$ Total & 415 & 510 & 81,37 & Baik \\
\hline
\end{tabular}

Dari keseluruhan kriteria Model DeLone dan McLeon untuk kesuksesan sistem informasi hasilnya Baik sebesar $81,37 \%$.

\section{KESIMPULAN}

Kesimpulan kegiatan pengabdian kepada masyarakat di SMK Negeri Sukoharjo yaitu aplikasi keuangan komite sekolah merupakan solusi yang utama dalam menyelesaikan permasalahan pada mitra, sehingga dapat melakukan pengelolaan keuangan komite sekolah secara transparansi dan realtime untuk dapat diketahui oleh seluruh anggota komite sekolah dengan memanfaatkan teknologi informasi yang ada.

Dalam menghasillkan sistem informasi keuangan komite sekolah secara transparansi dan realtime, aplikasi telah dihosting pada server yang dimiliki oleh sekolah, sehingga anggota komite atau pengurus komite dapat mengetahui keuangan komite sekolah dengan memanfaatkan teknologi informasi untuk mengakses aplikasi sehingga bagian keuangan tidak harus membuat rekapitulasi keuangan komite sekolah untuk dilaporkan kepada anggota atau pengurus komite.

\section{UCAPAN TERIMA KASIH}

Terima kasih kami ucapkan kepada jajaran perangkat SMK Negeri Sukoharjo Pringsewu. Selanjutnya ucapan terima kasih kepada LPPM dan Univeristas Teknokrat Indonesia atas dukungan yang diberikan, sehingga kegiatan pengabdian ini terlaksana dengan baik dan lancar. 


\section{Daftar Pustaka}

1. Ahdan, S., \& Sari, P. I. (2020). Pengembangan aplikasi web untuk simulasi simpan pinjam (studi kasus: lembaga keuangan syariah bmt 1-risma. Jurnal Tekno Kompak, 14(1), 33-40. Available at https://ejurnal.teknokrat.ac.id/index.php/teknokompak/article/view/382

2. Ahmad, H. S., Ratnasari, A., Informasi, J. S., Mercu, U., \& Jakarta, B. (2019). Perancangan Sistem Informasi Administrasi Sekolah Dengan Memanfaatan Dana Kartu Jakarta Pintar ( Kjp ) Berbasis Web ( Studi Kasus: Smp Darrosta Jakarta ). XVII(April), 178-186.

3. Andriyanto, D., Baridwan, Z., \& Subekti, I. (2019). Anteseden perilaku penggunaan ebudgeting: Kasus sistem informasi keuangan desa di Banyuwangi, Indonesia. Jurnal Dinamika Akuntansi Dan Bisnis, 6(2), 151-170. https://doi.org/10.24815/jdab.v6i2.13938

4. Atmadja, A. T., \& Saputra, A. K. (2017). Pencegahan Fraud dalam Pengelolaan Keuangan Desa. Jurnal Ilmiah Akuntansi Dan Bisnis, 12(2), 7-16. https://doi.org/10.24843/JIAB.2017.v12.i01.p02

5. Kaleb, B. J., V. P. K. Lengkong., R. N. Taroreh. (2019). Penerapan Sistem Informasi Manajemen Dan Pengawasannya Di Kantor Pelayanan Pajak Pratama Manado. Jurnal EMBA: Jurnal Riset Ekonomi, Manajemen, Bisnis Dan Akuntansi, 7(1), 781-790. https://doi.org/10.35794/emba.v7i1.22555

6. Kumala, N. K. R., Puspaningrum, A. S., \& Setiawansyah, S. (2020). E-Delivery Makanan Berbasis Mobile (Studi Kasus: Okonomix Kedaton Bandar Lampung). Jurnal Teknologi Dan Sistem Informasi, 1(2), 105-110. Available at http://jim.teknokrat.ac.id/index.php/sisteminformasi/article/view/607

7. Maulida, S., Hamidy, F., \& Wahyudi, A. D. (2020). Monitoring Aplikasi Menggunakan Dashboard Untuk Sistem Informasi Akuntansi Pembelian Dan Penjualan. Jurnal Tekno Kompak, 14(1), 47-53. https://doi.org/10.33365/jtk.v14i1.503

8. Setiawan, R., \& Nurjaman, R. (2017). Perancangan Sistem Informasi Keuangan di Sekolah Menengah Atas Negeri 18 Garut. Jurnal Algoritma, 14(2), 228-234. https://doi.org/10.33364/algoritma/v.14-2.228

9. Setiawansyah, S., Sulistiani, H., \& Saputra, V. H. (2020). Penerapan Codeigniter Dalam Pengembangan Sistem Pembelajaran Dalam Jaringan Di SMK 7 Bandar Lampung. Jurnal CoreIT: Jurnal Hasil Penelitian Ilmu Komputer Dan Teknologi Informasi, 6(2), 89-95. Available at http://ejournal.uin-suska.ac.id/index.php/coreit/article/view/10679

10. Sulistiani, H., Miswanto, M., \& Damayanti, D. (2020). Penerapan Metode Cost and Benefit Analysis Dalam Pengukuran Investasi Teknologi Informasi (Study Kasus: CV Laut Selatan Jaya). Jurnal Tekno Kompak, 14(1), 54-61. https://doi.org/10.33365/jtk.v14i1.469

11. Yana, S., Gunawan, R. D., \& Budiman, A. (2020). Sistem Informasi Pelayanan Distribusi Keuangan Desa Untuk Pembangunan (Study Kasus: Dusun Srikaya). Jurnal Informatika Dan Rekayasa Perangkat Lunak, 1(2), 254-263. https://doi.org/10.33365/jatika.v1i2.621 